\title{
Enthesitis and ankylosis in spondyloarthropathy: What is the target of the immune response?
}

\author{
J Braun, M A Khan, J Sieper
}

A report from a symposium held at Klinikum Benjamin Franklin,
Free University, Berlin, Germany, 25-26 February 2000

This symposium was organised by J Braun and J Sieper (Free University, Berlin) to review the current knowledge of the anatomical, inflammatory, microbiological, and immunological events in enthesitis.

The term "enthesopathy" is relatively new and its medical history short, but some important contributions can be listed (box 1).

\section{Box 1 History of "enthesopathy"}

- 1966 Enthesopathy first used by Niepel

- 1970 Entheses centrally affected in ankylosing spondylitis, in contrast with rheumatoid arthritis (RA; Heberden oration lecture by Ball)

- 1975 Some enthesitis in sacroiliitis (François)

- 1983 Syndrome of seronegative enthesopathy and arthropathy in children (Rosenberg)

- 1982 Sacroiliitis starts in the subchondral bone (Shichikawa)

- 1991 Enthesopathy discriminative feature of spondyloarthropathy ( $\mathrm{SpA}$; European Spondyloarthropathy Study Group criteria, Dougados)

- 1998 Entheses more commonly affected in arthritis in SpA compared with RA (McGonagle)

Department of

Rheumatology, UK

B Franklin, Free

University, Berlin,

Germany

J Braun

M A Khan

J Sieper

Correspondence to:

Professor J Braun,

Department of

Rheumatology, Medizinische

Klinik IV,

Universitätsklinikum

Benjamin Franklin,

Hindenburgdamm 30, 12200

Berlin, Germany

jbraun@zedat.fu-berlin.de

Accepted 9 August 2000

The spondyloarthropathies are among the most common inflammatory rheumatic diseases. ${ }^{1}$ In addition to the strong genetic predisposition, partly due to HLA-B27, ${ }^{2}$ there are characteristic clinical features of $\mathrm{SpA}^{3}$ : inflammatory back pain often due to sacroiliitis ${ }^{4}$ and enthesitis occurring mostly at various well defined locations, predominantly of the legs, such as the Achilles tendon, the plantar aponeurosis, the knee, the trochanter regions of the femur, and several pelvic sites. ${ }^{5}$ Thus entheses are ubiquitous, resulting in a diversity of associated pathological manifestations.

Sacroiliitis is the most common early sign of SpA. ${ }^{6}$ Whether or not ligamentous and enthe- seal structures are affected in sacroiliac inflammation has not yet been entirely clarified. To answer some of the most critical questions an expert symposium on enthesitis was organised: - Why are enthesis related structures affected?

- Is the presence of fibrocartilage essential?

- Do we have to change the concept of enthesitis or that of enthesis? More structures are affected than the conventional concept of enthesis implies. What about the blood supply of such structures?

- Is enthesitis an inflammatory process? Is it due to an immune response, trauma/ mechanical stress, or both?

- Where does the inflammation start?

- Is the new bone formation and ankylosis a pathological process itself, or is it no more than a reaction to severe and persistent inflammation?

- What is the link between inflammation and new bone formation?

- Which molecules might be the target of an immune response?

\section{Anatomy}

To understand the pathology of SpA, detailed knowledge about the anatomy of the affected structures is needed.

The enthesis is defined as the site of insertion of a tendon, ligament, joint capsule, or fascia to bone. Thus a variety of anatomical sites can be symptomatically affected in enthesopathy (box 2).

The anatomy of peripheral entheses was dis-
Box 2 Entheseal structures most commonly affected in SpA

- Achilles tendon

- Fascia plantaris

- Pes anserinus

- Trochanter major

- Ischial tuberositas

- Iliac crest

- Epicondylus humeri lateralis 
cally two major types of entheses (table 1): the fibrocartilaginous and the fibrous type. ${ }^{7}$ The fibrous type of enthesis is characterised by pure
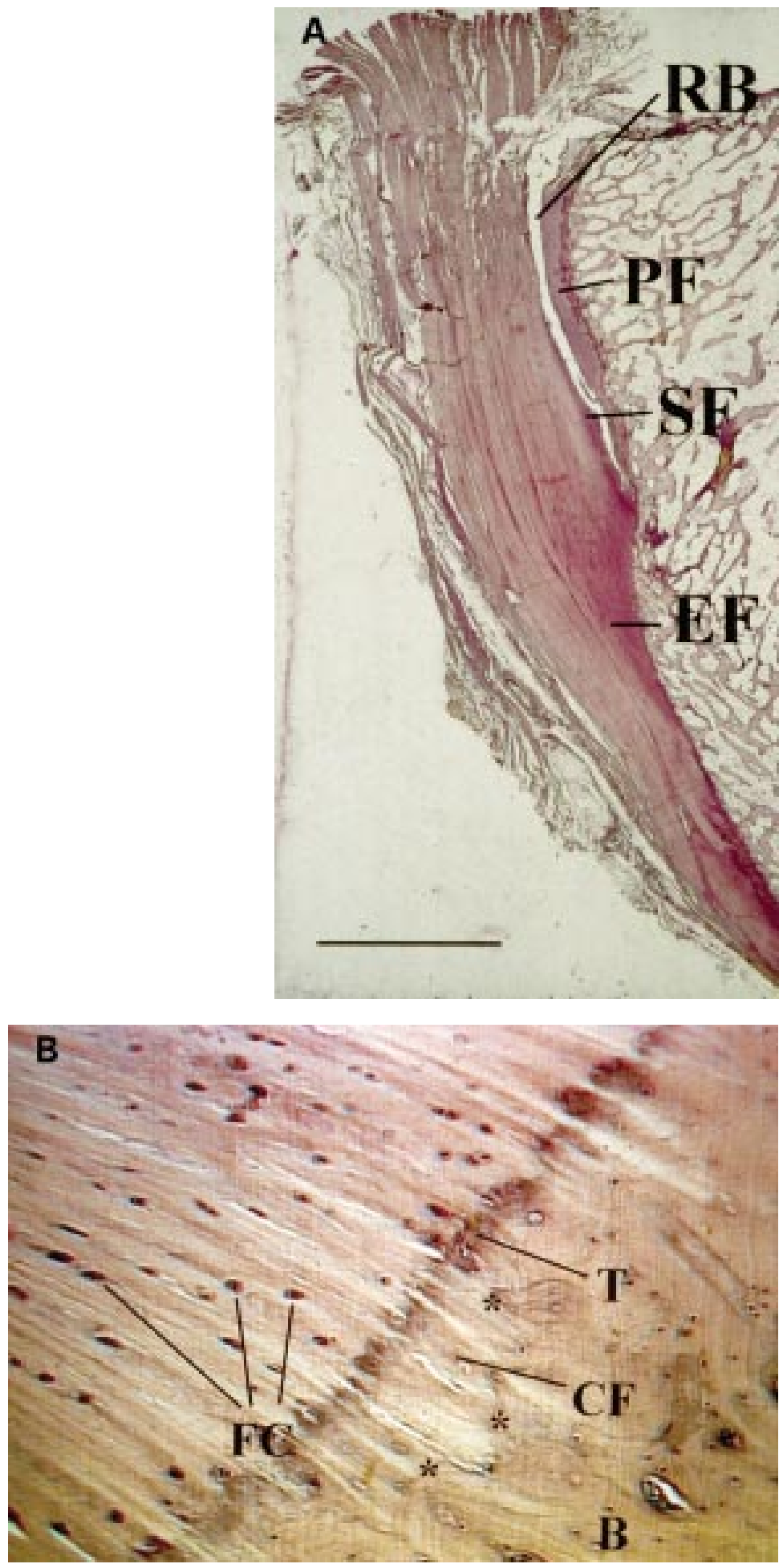

Figure 1 (A) Low power view of the attachment of the Achilles tendon to the calcaneus to show the complexity of structures that jointly comprise the enthesis. These structures include the enthesis fibrocartilage (EF), sesamoid fibrocartilage (SF), periosteal fibrocartilage $(P F)$, and the retrocalcaneal bursa (RB). Toluidine blue. Scale bar $0.5 \mathrm{~cm}$. (B) A high power view of the enthesis of the supraspinatus tendon in the region of the tidemark $(T)$. This highly basophilic line is a calcification front separating the zones of calcified and uncalcified fibrocartilage. It is relatively straight and this contrasts with the irregularity of the junction between the calcified fibrocartilage (CF) and the underlying bone (B) (junction marked with ${ }^{\star}$ ). It is such interdigitations that help to hold the two tissues together. Note that the fibrocartilage cells (FC) are more conspicuous in the region of uncalcified fibrocartilage. Haematoxylin and eosin. Scale bar $100 \mu \mathrm{m}$. (Courtesy of Dr M Benjamin, University of Cardiff, Wales.) dense fibrous connective tissue that attaches the tendon or ligament to the bone, ${ }^{8}$ whereas the fibrocartilaginous type is characterised by a transitional zone of fibrocartilage (FC) at the bony interface (fig 1). Fibrous entheses are typical of the metaphyses and diaphyses of long bones, but most entheses are fibrocartilaginous - for example, the sites of tendon insertions into the epiphyses of long bones. ${ }^{9} \mathrm{FC}$ is most typical of tendons and ligaments where the angle of attachment changes throughout the range of joint movement. The site at which synovial joint capsules insert into the bone can also be regarded as an enthesis containing FC. ${ }^{10}$

The fibrocartilaginous entheses have four components:

- The tendon with characteristic sparse longitudinally orientated fibroblasts-that is, dense fibrous connective tissue

- A zone of uncalcified FC where the cell morphology changes to that of chondrocytes

- An abrupt transition to calcified FC

- Bone.

As shown by Benjamin some ligaments have both types of insertion, such as the medial collateral ligament of the knee joint. ${ }^{11}$ This ligament has a fibrocartilaginous enthesis on the femoral epiphysis but a purely fibrous attachment to the tibial metaphysis. An immunohistochemical study of the medial collateral ligament during the postnatal growth period of rats showed that the entheseal cartilage at the femoral attachment is initially derived from the cartilaginous bone rudiment. However, it was found to be quickly eroded on its deep surface by endochondral ossification as bone formed at the attachment site. Later, it was replaced by FC. Thus enthesis FC is a dynamic tissue with the inherent ability to promote bone formation. This is of particular interest in SpA with regard to ankylosis. It is not clear whether enthesitis in $\mathrm{SpA}$ involves only insertions containing FC.

The embryologic development of enthesis is characterised by the primitive tendon or ligament attaching to the cartilage. Metaplasia of fibroblasts at this attachment site results in the formation of FC, and this process then extends further into the tendon or ligament, while the remainder of the cartilage undergoes endochondral ossification. The regions of tendons and ligaments that make up the entheses are dynamic structures with a high capacity for tissue turnover so as to respond continually to changing mechanical factors.

There is a sharp borderline between calcified and uncalcified cartilage, which is called the tidemark. In contrast with the tidemark region, the junction between calcified FC and bone is highly irregular, with little direct continuity of collagen fibres penetrating directly into the bone trabeculae. These Sharpey fibres may provide additional anchoring support to bone. The uncalcified FC zone creates a vascular and cellular barrier. This is prominent at sites where joint movement results in a great deal of bending of ligaments/tendons, probably because the FC helps to reduce wear and tear by stress dissipation, as does the articular cartilage. The tidemark between the uncalcified and 
Table 1 The two types of enthesis

\begin{tabular}{lll}
\hline & Fibrocartilaginous enthesis & Fibrous enthesis \\
\hline Origin & Cartilage & Tendon, ligament, periosteal \\
Traject of fibres & End within cartilage & Penetrate into bundle bone \\
Attachment site & Epiphyses, apophyses & Metaphyses, diaphyses \\
Collagen type & II & I \\
Glycosaminoglycans & Present & Absent \\
Example & Achilles tendon, annulus fibrosus & Perivertebral ligaments \\
& SIJ` ligament & SIJ ligament \\
\hline
\end{tabular}

${ }^{\star} \mathrm{SIJ}=$ sacroiliac joint.

the calcified FC is very close to the subchondral bone. Tendon/ligament failures at FC entheses, clinically and experimentally, often occur at the level of the subchondral bone, suggesting that this region is weaker than the transitional region between soft and hard tissue. ${ }^{12}$ The overall significance of this barrier between bone and ligament, osteocytes and fibroblasts, is not clear.

At the insertion site of the Achilles tendon, three types of FC can be differentiated: two are located in the distal tendon (entheseal and sesamoid) and one proximal to the heel bone $\left(\right.$ periosteal ${ }^{13}$ ). The entheseal FC allows for a gradual transition of mechanical properties between tendon and bone. The periosteal and sesamoid FC, which lie anterior and posterior to the retrocalcaneal synovial bursa respectively, help the tendon to withstand compression against the heel. ${ }^{9}$ As proposed by Benjamin, these associated fibrocartilages can also be considered as a part of the enthesis. ${ }^{5}$

The suggestion of Khan was discussed to broaden the concept of enthesis even further to include the sites of the cartilage attachment to bone. This proposal would imply that the chondral-subchondral junction of bone where cartilage, rather than exclusively ligament/ tendon, attaches to the bone, is also regarded as an enthesis. The basis of this idea comes from the histopathological studies of Shichikawa et $a l^{14}$ and recent magnetic resonance imaging (MRI) studies, in which patients with early stages of SpA commonly show inflammatory subchondral bone changes. ${ }^{15}$

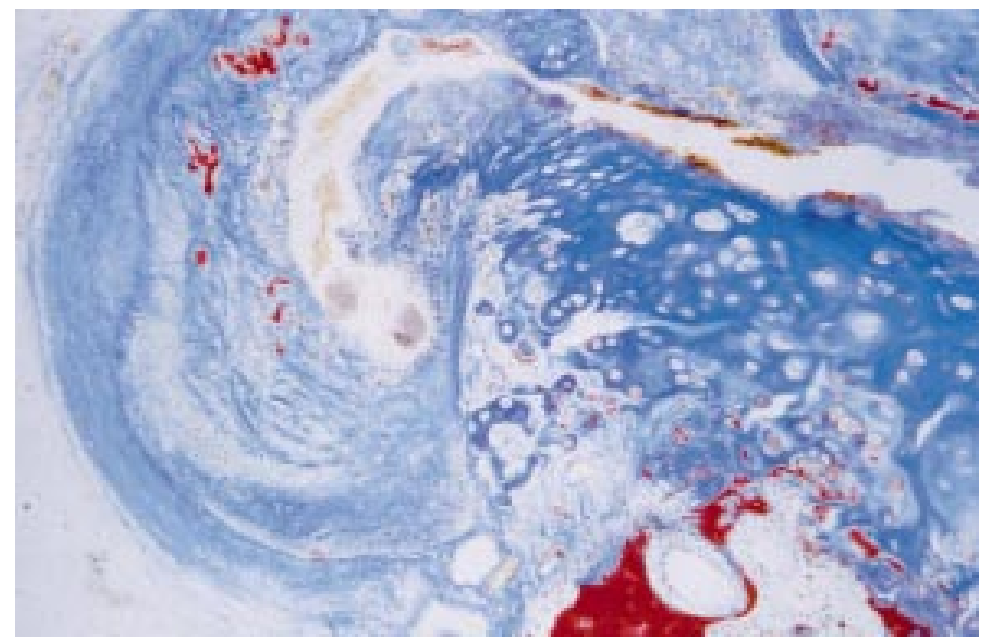

Figure 2 Low power view of a normal sacroiliac joint showing the synovial membrane (left) and its attachment to the cartilage (centre), the bone marrow at the right bottom with the attached subchondral bone and cartilage above and numerous blood vessels in the subchondral area. (Courtesy of Professor D Gardener, University of Edinburgh, Scotland.)
Should the anatomical concept be changed because the disease does not accept histological borders? In contrast, it seems more logical to change the concept of the disease. Thus the concept of specific inflammation in SpA should no longer remain restricted to entheses but has to be extended to subchondral bone, the bone marrow, and the joint capsule. One common denominator for these structures is the presence of FC (fig 1). Thus FC might be the centrally involved anatomical structure in SpA. This needs to be further investigated.

Another important anatomical feature is the ubiquitous presence of blood vessels at the sites where synovium, joint capsule, subchondral bone, and bone marrow come close, as shown by $\mathrm{D}$ Gardener in the case of a normal sacroiliac joint (fig 2). If the transport of antigens such as bacteria associated with reactive arthritis to these structures is the initial trigger of inflammation it is there where the bloodstream takes them.

Furthermore, common ossification processes, such as enthesophytes, are preceded by vascular invasion. ${ }^{16}$ Ball already described capillary-like vessels that are seen close to the bone and pass through the enthesis to the marrow to Haversian canals. Although the vessels histologically seem quite scanty, the vascular bed of the entheses seems fairly large according to early experiments using labelled phosphorus. ${ }^{17}$ There is a definite role for new blood vessels in endochondral bone formation. As discussed by Braun, vascular endothelial growth factor, an essential mediator of angiogenesis in growing cartilage, ${ }^{18}$ has not been searched for in these regions to date.

Although the topic was not directly discussed during the workshop, entheses probably derive their nutrition from a number of sources: (a) small perforating vessels that are branches of surrounding periosteal arteries that form an anastomosis around the base of the enthesis, $(b)$ vessels in the associated bone marrow, and $(c)$ vessels that supply from the pure fibrous region of the tendon or ligament. Entheses are well innervated with proprioceptive and pain receptors.

\section{Histopathology}

The histopathology of spinal entheses was discussed by François, from Brussels, Belgium. Synovitis, pannus formation, superficial cartilage destruction, myxoid bone marrow, enthesitis, intra-articular fibrous strands, new bone formation, and bony ankylosis all occur in ankylosing spondylitis (AS) sacroiliac joints (fig 3). Cartilaginous fusion is also seen in control groups but occurs earlier in AS. As reported by Francois, mild but destructive synovitis and myxoid subchondral bone marrow are the earliest changes identified histologically. ${ }^{19} 20$ There is only limited inflammation not only at entheseal sites in the sacroiliac joint. ${ }^{20}$ Similarly, in the experience of Braun using MRI, ${ }^{21}$ in early cases sacroiliac inflammation starts near the joint capsule (fig 3). As already pointed out, vessels are abundant in the region where subchondral bone, capsule, and 


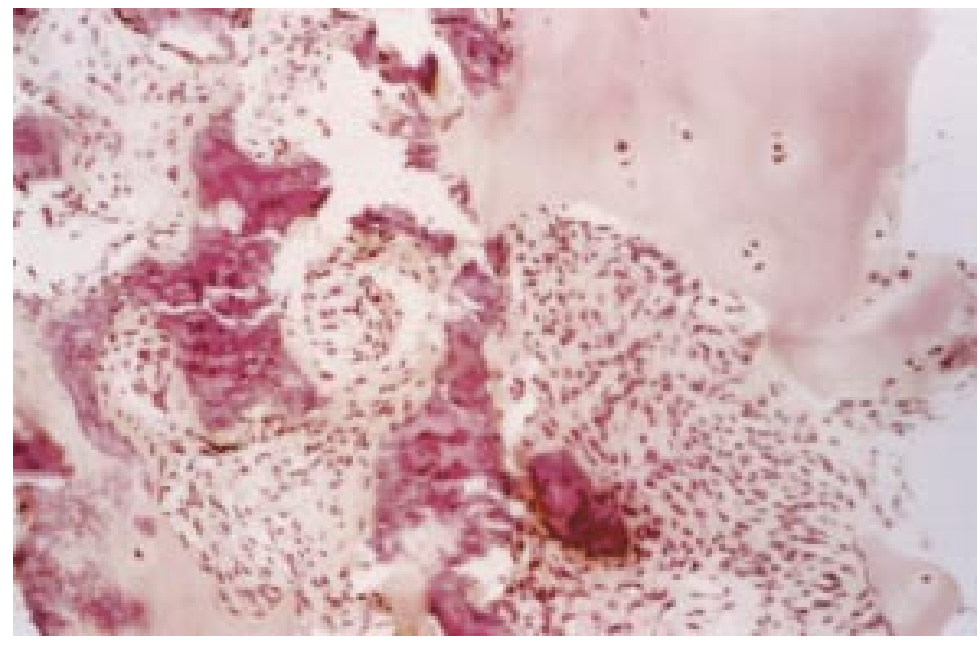

Figure 3 Sacroiliac joint biopsy specimen of a 29 year old male patient with ankylosing spondylitis and bilateral inflammatory low back pain located to the right side and a disease duration of 7.5 years. The biopsy specimen shows a subchondral cellular infiltrate partly invading the cartilage. Fibroblasts and activated lymphocytes are seen in the infiltrate. In between are areas of calcification and bone formation. (Haematoxylin and eosin staining, magnification $250 \times$.) at its chondroid enthesis, in the deeper perivertebral ligaments, and at their insertion by Sharpey's fibres. An unusual form of chondroid metaplasia contributes to ankylosis and bony fusion. Soft tissue inflammation and bone destruction occur at entheseal sites, and inflammatory fibroblastoid cell infiltrates invade the bone that is adjacent to the entheseal site, and also the subchondral bone. ${ }^{21}$ The precise role and origin of these cells is incompletely understood.

Studies by de Vlam from Gent, Belgium, suggest that ankylosis of the zygoapophyseal joint occurs before the appearance of bony syndesmophytes at the same level. ${ }^{22}$

Claudepierre, from Paris, France, studied orthopaedic hip surgery specimens from eight patients with $\mathrm{SpA}$, four with RA, and three with osteoarthritis (OA). Inflammatory infiltrates and oedema were clearly predominant in the bone marrow of $\mathrm{SpA}$ specimens close to the enthesis, and the inflammatory cells were predominantly $\mathrm{T}$ lymphocytes. ${ }^{23}$ There was a four- to fivefold increase of CD $3+\mathrm{T}$ cells in SpA compared with RA. The CD3+ cells were clearly more common than CD20+ cells in $\mathrm{SpA}$, but not in RA. In comparison with earlier studies in sacroiliitis ${ }^{24} \mathrm{CD} 8+\mathrm{T}$ cells were more commonly found in hip joints. ${ }^{23}$ A possible explanation is the different stage of disease of the patients undergoing endoprosthesis.

FitzGerald, from Dublin, Ireland, studied synovial changes in psoriatic arthritis (PsA), focusing on $\mathrm{T}$ cells and on the increased vascularity of the synovium. CD4+ T cells predominate in the synovial membrane during active disease, but CD8+ cells outnumber CD4+ cells by $2: 1$ in the synovial fluid. The CD8+ T cells appear to be clonally expanded, and an antigen-specific $\mathrm{T}$ cell mediated immune event seems to occur in the synovial membrane in PsA. $^{25}$

The extensive pathological studies of AS and PsA by Fassbender ${ }^{26}{ }^{27}$ indicate that the new bone formation in these diseases takes the form of desmal ossification at the enthesis junction with bone, and also by endochondral ossification at sites where cartilage is present. Signs of inflammation are not present at these sites. BMP-6 transgenic mice that develop PsA-like arthropathy with florid periostitis show an analogous joint histopathology. ${ }^{28}$

Fassbender published several papers together with Schilling on the subject in the 1970 s, in which the entheses were recognised as an essential part of the SpA concept, which they introduced into German rheumatology. Schilling recently discussed the relation between the SAPHO syndrome and the SpA concept. ${ }^{29}$

\section{joint (fig 4).}

Destruction of adjacent articular tissues is followed by scarring by fibrous tissue, woven bone, and new cartilage. The original cartilages fuse, and this is the predominant mechanism of early ankylosis. In the spine the diarthrodial joints exhibit either synovitis or enthesitis, with capsular ossification, myxoid bone marrow changes, chondroid metaplasia, synchondrosis, and ossification. Inflammatory changes are seen all along the annulus fibrosus, particularly

\section{Biochemistry}

The axial skeletal hyaline and FC resist compressive forces resulting from mechanical stress. FC cells are large and oval and often packed with intermediate filaments which are affected in the transduction of physical forces. ${ }^{30}$ During differentiation FC cells accumulate at a time that corresponds to increasing mechanical load. Entheseal FC cells are surrounded by a 
metachromatic pericellular matrix, in which proteoglycan molecules are visible. ${ }^{31}$ At the entheses these cells do not communicate with each other via gap junctions in contrast with the midsubstance of a tendon. ${ }^{32}$ In the enthesis, as in articular cartilage, its ability to resist compression is linked to the presence of aggrecan and type II collagen in the extracellular matrix. These molecules have been demonstrated at several entheses by reverse transcriptase-polymerase chain reaction, western blotting, and/or immunohistochemistry. At most sites, they are synthesised by FC cells that appear relatively late in development by fibroblast metaplasia. In the inner annulus, however, FC cells are derived from hyaline cartilage that is present during early development. ${ }^{11}$

Fibrous and fibrocartilaginous regions of a tendon respond differently in their extent of cell division and matrix synthesis to the addition of growth factors such as IGF1 that are aimed at encouraging repair. ${ }^{14}$ There are marked changes in the glycosaminoglycan (GAG) distribution: both types of enthesis have dermatan sulphate throughout life but only the fibrocartilaginous insertions have keratan sulphate (after 45 days of development) and chondroitin 4 and 6 sulphate. ${ }^{33}$ The latter, as pointed out by Benjamin, is the most consistent surface marker of FC. ${ }^{34}$ Of interest, much of the GAG is associated with the large aggregating proteoglycan aggrecan that is characteristic of articular cartilage. The many GAG side chains attached to the core protein aggrecan, in turn linked to a central hyaluron molecule, create a highly negative charge. This leads to the formation of domains with high osmotic pressure and the ability to imbibe water significantly in order to withstand compression.

Types I and III collagen are the major collagens found in the Achilles tendon and its FC; their major function is to provide tensile strength. FC has properties intermediate with those of very dense connective tissue and hyaline cartilage. ${ }^{9}$ Type II collagen mRNA was consistently found at the enthesis but not at mid-tendon, and proteoglycan aggrecan mRNA was found at a higher level in the enthesis than in mid-tendon. ${ }^{33}$ The ability of the entheseal FC to resist compression is the result of the presence of type II collagen and aggrecan in the extracellular matrix, synthesised by FC cells that develop by fibroblast metaplasia.

Heinegård from Lund University, Sweden, reviewed the biochemistry of cartilage matrix. The matrix, a composite tissue with mechanical function, can remodel itself by the actions of chondrocytes to respond to changing functional requirements. Its major constituents are the collagen fibres that provide tensile properties, and the negatively charged aggrecan macromolecules that provide osmotic pressure to retain water and restrict its movement. Minor components that have a key role in regulating the matrix assembly and in signalling the chondrocytes about the condition of the matrix, include a family of leucinerich proteins called leucine-rich repeat pro- teins. They are present in the extracellular matrix of cartilage, and also in entheses and tendons. They include the collagen binding proteoglycans such as decorin, biglycan, fibromodulin, and lumican, that play a major part in interlinking collagen fibres and in the assembly of the collagen network. This family also includes molecules not containing GAG chains, and some of them, such as chondroadherin and osteoadherin, are likely to have a role in mediating signals from matrix to chondrocytes for monitoring tissue function and maintaining structural integrity.

A molecule called cartilage oligomeric matrix protein (COMP), which is expressed in cartilage and tendon, binds to collagen molecules to help form collagen fibres. ${ }^{35}{ }^{36}$ The molecule has five binding sites and, possibly, may induce pathogenic complexes. In early stages of OA, chondrocytes express more COMP, fibronectin, and a protein called class II associated invariant chain peptide, possibly as a repair-type response. The proteoglycan fragment release in the urine is high in the early stages, and it decreases at later stages when OA changes can be seen by roentgenography. Heinegard pointed out that he had not studied $\mathrm{SpA}$, but, from his perspective, COMP at cartilage-bone interface is also worth investigating in SpA.

There is a need to characterise further the biochemistry of the enthesis, which has not been well defined, partly because of the relative inaccessibility of this site (box 3). Any age related differences in gene expression also need to be investigated as $\mathrm{SpA}$ are uncommon after the age of 40 , which may reflect biochemical changes at the enthesis with passage of time, such as progressive cross linking of human tendon collagen with increasing age. The distribution and expression of proteoglycan aggrecan and type II collagen are important because autoimmunity to these molecules in mice can result in arthritis. Interestingly, both these antigens are expressed in the FC within the enthesis and also at other sites of inflammation in $\mathrm{SpA}$.

\section{Box 3 Biochemistry of the enthesis}

- Collagens I, II, III, V, VI, IX, X, XI

- Decorin

- Biglycan

- Fibromodulin

- Lumican

- Versican

- Aggrecan

\section{Animal models}

Zhang, from McGill University, Montreal, Canada, discussed the BALB/C mice that develop arthritis and spondylitis reminiscent of human $\mathrm{SpA}$ in response to immunisation with human proteoglycan aggrecan in complete Freund's adjuvant, ${ }^{37}$ and also when one uses only its G1 domain instead of the whole aggrecan molecule. The inflammatory lesions are characterised by initial mononuclear cell infil- 
tration into the outer margins of the annulus fibrosus at the entheseal insertions to the vertebrae, as seen in AS. The inflammation is associated with angiogenesis that progresses to destructive lesions of the end plates and progressive discitis. ${ }^{38}$ Their studies of $\mathrm{T}$ cells specific for the G1 epitope have shown that local generation and release of the immunogen or fragments thereof would lead to T cell homing, with resultant inflammatory damage that would lead to further release of epitope, attracting further disease inducing $\mathrm{T}$ cells. ${ }^{39} 40$ Moreover, cytokines may cleave hyaluronic acid, while metalloprotease and aggrecanase enzymes may cleave the interglobular region to release the G1 domain of aggrecan in enthesis, cartilage, and disc. Zhang is currently studying peptides derived from the G1 domain that bind to human major histocompatibility complex molecules. According to him, this region can potentially provide 20 peptides that have the HLA-B27 binding motif.

Cellular immunity to proteoglycan was reported in patients with AS some years ago. ${ }^{40}$ Proteoglycans, including G1 or other homologous proteins, can be found in anatomical sites known to play a part in AS, such as the entheses, the uvea, the aorta, and the aortic valve. ${ }^{41}$ Proteoglycans bind to hyaluronic acid, and the binding is stabilised by the associated link protein which may play a part in autoimmune processes in RA. ${ }^{42}$ The pattern and distribution of the proteoglycans, aggrecan and versican, varies. For example, smooth muscle cells in arterial tissues synthesise versican, and bone osteoblasts, cells at the mid-tendon level, and, to a lesser extent, in the enthesis, also produce versican, which serves the role of aggrecan in environments subjected to cyclical compression. Such compression and relaxation also occurs in the anterior uveal tract of the eye in order to focus the lens. Interestingly, molecules have been seen at that site in the eye that are immunoreactive with antibodies to aggrecan and link protein. Thus trauma and/or inflammation due to infection, in the presence of immunogenetic predisposition, may permit a loss of $\mathrm{T}$ cell tolerance that leads to immunity to the G1 domain of aggrecan, link protein, or other molecules at the affected sites, resulting in tissue damage at specific sites in AS.

Kriegsmann from the University of Mainz, Germany, discussed joint pathology in HLAB27 transgenic rats from the $21-4 \mathrm{H}$ line that develop gut inflammation and rheumatic manifestations resembling human SpA. He noted that the primary event is synchondrosis - that is, fusion between the opposing articular cartilages of the joint, and all the 12 animals killed at 7 months of age showed fusion of vertebral bodies by cartilaginous tissue. He speculated that this may be due to alteration of cartilage biochemistry or surface properties. The next stages are the degeneration of the cartilage, proliferation of chondrocytes, and invasion of fibroblastic tissue from the subchondral bone. Syndesmophyte formation was seen in the spine. Synchondrosis and subchondral erosions were present in the sacroiliac joints in $50 \%$ of the animals, and $40 \%$ of knee joints showed such changes. Furthermore, cartilage metaplasia could be detected at patellar tendon enthesis. The paws showed severe destructive lesions in $25 \%$ of the animals, along with cartilage metaplasia, synchondrosis, invasion of fibroblastic tissue into subchondral bone, and inflammation of adjacent muscles, but there was only mild synovitis. Thus in the animal model the inflammatory process primarily starts just beneath the cartilage and invades the cartilage and the bone. ${ }^{43}$

Eulderink, from Delft, the Netherlands, described the joint histopathology of ankylosing enthesitis, a naturally occurring progressive stiffening of the ankle and/or tarsal joints in C $57 \mathrm{BL} / 10$ mice. ${ }^{44}$ It is seen in up to $30 \%$ of male animals, and hardly at all in female animals. In contrast with $\mathrm{AS},{ }^{45}$ the sacroiliac joints, spine, eyes, or other organs are not affected. Ankylosing enthesitis usually starts at the age of 4 to 8 months, develops during a period of two to four weeks, and then remains stable. In HLA-B ${ }^{\star} 2702$ transgenic mice an increased frequency of this ankylosing enthesopathy has been reported, but this does not markedly affect the severity or the type of lesions. ${ }^{46}$ The disease starts with a short phase of proliferative inflammation of the joints and adjacent tissues of the paw that lasts for two to three weeks. There is some fibrinous exudation and leucocytic infiltration. This brief and scarcely destructive process leads to proliferation of cartilaginous cells at entheseal attachments of capsules, ligaments, and tendons to bone. Fusion of joint cartilage (synchondrosis), marginal ankylosis, and subsequent ossification of the cartilage proliferations and some dermal ossification lead to large bony bridging (syndesmophytes) and ligamentous calcification that limits joint mobility. This ankylosis mainly affects the margins of the joints of the paw, whereas the central cartilage of the affected joints remains intact for a long time. ${ }^{46}$

\section{Immunology}

The molecular and cellular mechanisms of disease causation are still unknown despite intensive investigation. ${ }^{47}$ Some evidence indicates that $\mathrm{T}$ cells and macrophages are involved, ${ }^{24} 48$ but the role for bacterial antigens is less clear because microbial DNA has been detected in peripheral joints but not the sacroiliac joints. ${ }^{49}{ }^{50}$ Furthermore, DNA of more bacteria than expected has been detected in both arthritic $^{51}$ and normal joints. ${ }^{52}$

It is postulated that $\mathrm{AS}$ and related SpA result from autoreactive $\mathrm{T}$ cells that are activated by external antigenic (bacterial) challenge, and then recognise endogenous peptides presented by HLA-B27. ${ }^{47}$ This arthritogenic peptide hypothesis implies that arthritis is triggered by a $\mathrm{T}$ cell response to a specific antigenic peptide or peptides (derived from the triggering bacteria and/or from an autoantigen) that can preferentially be bound to disease associated HLA-B27 subtypes, which are thus presented in an HLA-B27 restricted fashion to effector CD8+ T cells. Arthritis can be induced in rodents by first priming the $\mathrm{T}$ cells to respond to a foreign antigen, and then 


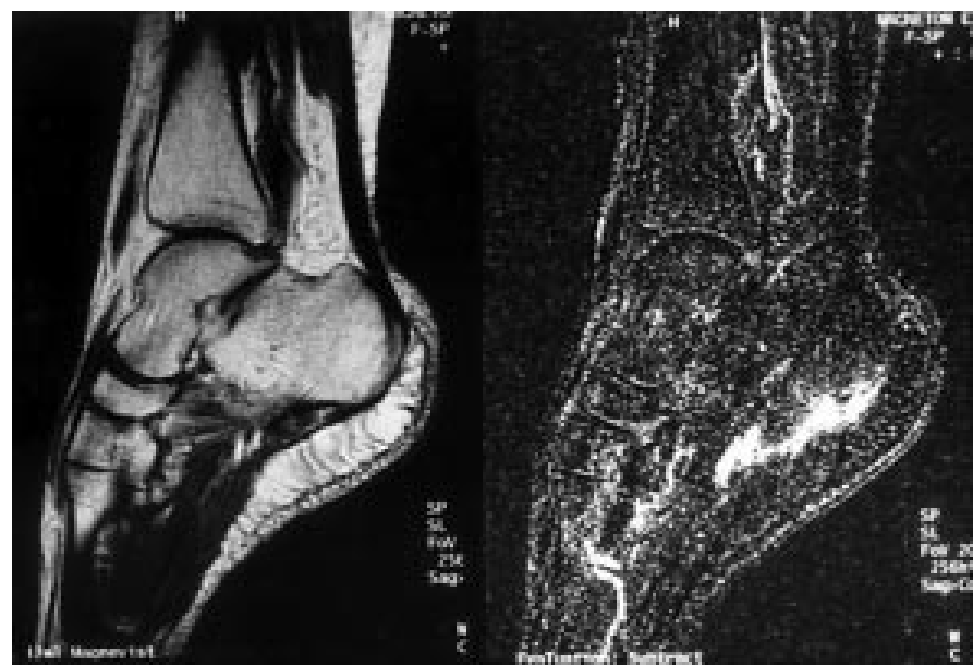

Figure 5 Magnetic resonance imaging subtraction image of a 32 year old $H L A-B 27+$ patient with undifferentiated spondyloarthropathy showing acute fasciitis plantaris (all the white appearing enhancement after gadolinium application corresponds to oedema and inflammation). Reproduced with permission of the copyright holders from Akt Rheumatol 2000;25:1-9.

challenging the animal with the antigen intra-articularly. This is similar to the situation in human reactive arthritis $(\mathrm{ReA})$, in which $\mathrm{T}$ cell responses are induced by the triggering microbe, and the microbial antigens reach the joints, probably via macrophages. The severity and persistence of the resulting arthritis are determined by genetic factors.

As pointed out by Sieper, Berlin, exposure to bacteria which trigger disease seems to be crucial to the pathogenesis of SpA. He put forward a hypothesis, needing further validation by future studies, that in HLA-B27+ patients with $\mathrm{SpA}$, a primary entheseal based pathology of synovial joints may result in secondary synovial changes that masquerade as synovitis. On the other hand, in HLA-B27- patients, the primary target may be the synovium, and the persistence of bacteria or their antigenic components in the joints may be sufficient to induce synovitis. The articular and extra-articular disease spectrum in HLA-B27+ patients may result, at least in part, from an autoimmune response to a cross reacting autoantigen triggered by bacterial immunogen(s) that may not necessarily persist (a "hit and run" event).

Given that a mostly silent bacterial infection not readily controlled by the host's immune system due to, for example, lower tumour necrosis factor $\alpha(\mathrm{TNF} \alpha)$ production, ${ }^{53}{ }^{54}$ is the initial event, either the microbes themselves or antigen-specific $\mathrm{T}$ cells would be expected to be transported by the bloodstream ${ }^{55}$ to the entheses and cause inflammation in this borderline tissue. ${ }^{56}$

\section{Clinical epidemiology}

Clinically, there is no doubt that entheseal structures play a part in SpA. The exact prevalence of enthesopathy in SpA and its subsets is difficult to assess because it is often impossible to delineate the clinical symptoms to defined anatomical structures. However, on the basis of published data we can assume that $10-60 \%$ of patients with SpA have clinically overt enthesi- tis, ${ }^{4}$ usually in combination with peripheral arthritis. Enthesitis seems to be most common in juvenile SpA, where it is a more obvious initial feature than sacroiliitis. ${ }^{57}$ In the ESSG criteria only enthesitis of the legs was taken as indicative of $\mathrm{SpA} .^{3}$

The tarsal ankylosing enthesitis in the animals with ankylosing enthesitis resembles the ankylosing tarsitis of Mexican Mestizo children that was described by Burgos-Vargas, from Universidad Nacional Autonoma de Mexico, Mexico City, Mexico. The enthesitis begins primarily in the feet, and the inflammatory phase of this enthesitis lasts for a mean duration of 1.9 months, though the range is quite wide. Some children have recurrent episodes of enthesitis affecting many sites and lasting for a longer time. No treatment seems effectively to stop this severely disabling disease process that results in bony ankylosis of joints of the feet. Most of these children later get fully fledged ankylosing spondylitis, and $95 \%$ have HLA-B27-primarily, the $\mathrm{B}^{\star} 2705$ subtype.

Leirisalo-Repo from Helsinki University, Helsinki, Finland, described the clinical significance of enthesitis in ReA, which is seen in up to $30 \%$ of such patients. This enthesitis seems to run a more chronic course than distinct arthritis. She carried out a case-control study of 405 patients with acute joint symptoms after campylobacter infection, the commonest gut infection in Finland, and of 405 uninfected controls. Acute joint symptoms were seen in $25.4 \%$ of patients and only $2 \%$ of controls. Among the campylobacter infected patients, $7.4 \%$ developed ReA, $5.4 \%$ had "reactive" arthralgia, 3\% had isolated "reactive" sacroiliitis, and $1 \%$ had isolated "reactive" enthesitis; these conditions were not seen among controls. The results indicate that enthesitis can be the only clinical manifestation in some patients with reactive musculoskeletal complications triggered by an enteric infection. From the studies of Leirisalo-Repo in salmonella triggered ReA we know that about $15 \%$ of patients develop chronic SpA. ${ }^{58}$

\section{Imaging}

What can we learn from modern imaging techniques for the localisation of inflammation in $\mathrm{SpA}$ ? In peripheral enthesitis, inflammatory processes in tendons and ligaments can be visualised by ultrasound ${ }^{59}$ and MRI, ${ }^{60}$ but it is also possible to document enthesitis in more hidden sites, such as the plantar aponeurosis (fig 5).

Although there is limited clinical evidence that reactive enthesitis or sacroiliitis exists without arthritis being present, the interesting hypothesis by McGonagle and colleagues implies that knee arthritis is mainly a feature of extensive enthesitis. ${ }^{6162}$ Anatomically this may indeed be the case because the knee joint has numerous intra-articular entheseal structures (including the chondral-subchondral junctions, cruciate and meniscal attachments) and entheseal sites (including the joint capsules, and insertions of numerous tendons and ligaments) adjacent to it. In a comparative MRI study knee arthritis of extra-articular ligamentous and entheseal structures was detected 
more commonly in patients with SpA than in those with RA.$^{61}$ There are no histological data on this issue so far.

Olivieri, from Potenza, Italy, McGonagle, from Leeds, UK, Bollow and Braun, from Berlin, discussed the imaging modalities of enthesitis. The conventional radiographic features of enthesitis include soft tissue swelling, osteopenia at entheseal bone insertions, bone cortex irregularity at insertion, and adjacent periostitis, as well as entheseal soft tissue calcification and new bone formation. These entheseal changes are not as readily appreciated in large joints as they are in the small joints of the hands, especially among patients with PsA. In contrast, conventional radiography and computed tomography mainly detect chronic changes. Dynamic (gadolinium enhanced) MRI and the use of short term inversion recovery and other fat suppression techniques show that the inflammatory response associated with enthesitis may be quite extensive. It affects not only the adjacent soft tissues but also the underlying bone marrow, where it can sometimes extend to a considerable distance away from the enthesis insertion.

The earliest lesion in AS is usually detectable in the sacroiliac joint, where the joint capsule enthesis and subchondral bone are probably the earliest sites affected. MRI provides evidence of bone marrow oedema and inflammation of structures in and around the joint capsule in some patients. The lumbar spine may also be affected early and skip lesions may be evident. This indicates that the spinal disease in early AS does not always extend in a orderly fashion from the sacroiliac joint upwards. Dynamic MRI is very helpful in the early diagnosis of sacroiliitis ${ }^{21}{ }^{63}$ and spinal disease in $\mathrm{AS}^{6465}$ when conventional radiographs are still normal, and the degree of gadolinium enhancement correlates with the diffuse histological changes. ${ }^{48}$ The entheseal bone oedema may be evident at sites devoid of synovium, such as the plantar fascia, and also at entheses adjacent to synovial joints. However, it may also be a non-specific response to biomechanical factors, as in trauma or osteoarthritis, or due to joint inflammation, fracture, infection, or malignancy.

Entheseal structures have a low water content and are therefore not well visualised on MRI; only the adjacent soft tissue and bone changes are best seen. High frequency real time ultrasonography is a relatively inexpensive method for assessing enthesitis, as it can demonstrate entheseal swelling, tendonitis, peritendinous soft tissue swelling, bursitis, and ligamentous and periosteal swelling. Enthesitis is associated with alterations of the normal fibrillar echo texture owing to decreased echogenicity of the enthesis by inflammation and oedema, and possibly bone erosion or new bone formation at the insertion. Combined MRI and ultrasonographic studies suggest that (a) entheseal soft tissue abnormalities may predate the onset of bone oedema, (b) SpA associated periostitis may be secondary to the diffuse enthesitis associated bone changes, and (c) the synovium may not be the primary target organ in AS and related SpA.

\section{New bone formation}

Development of new bone formation is the main factor in the spinal immobility associated with SpA. Ball, in his classic studies on enthesitis, suggested that the new bone formation is a reaction to the previous homeostasis and repair of skeletal structures. As discussed by Häupl from the Charité, Berlin, transforming growth factor $\beta$ (TGF $\beta$ ) may provide protective signals early during the inflammatory process but induces non-specific fibrosis upon chronic disease progression. TGF $\beta$ mRNA has been detected in sacroiliac joints of patients with $\mathrm{SpA} .{ }^{21}$ Overexpression of TGF $\beta$ and bone morphogenic proteins (BMPs) may induce pathological ossification, or promote disc degeneration. BMPs play a major part in ossification processes, ${ }^{66}{ }^{67}$ while the related growth and differentiation factors influence tendon and ligament formation. ${ }^{68} \mathrm{BMP}-2$ and $\mathrm{BMP}-4$ promote callus during healing processes after bone fracture. ${ }^{69} \mathrm{BMP}-2$ also enhances tendon to bone healing, but the presence of BMP-7 is inappropriate for tendon repair as it may induce pathological ossification. ${ }^{70}$ As noted earlier, the BMP-6 transgenic mice develop florid periostitis, suggesting that this cytokine may be important in new bone formation. ${ }^{28}$

The importance of enthesitis and new bone formation as skeletal phenomena in SpA has gained further support from another transgenic animal model not discussed at this symposium. A disease phenotype similar to human AS, with polyenthesitis, occurs in transgenic mice ${ }^{71}$ expressing a truncated $\mathrm{TNF} \alpha$ gene obtained from a mouse strain called Peromyscus leucopus. These observations confirm the importance of the role of proinflammatory and proosteoblastic cytokines in enthesitis associated disease.

Again, the important role of angiogenesis for bone formation has recently been shown by demonstrating that vascular invasion of cartilage is necessary for proper bone formation. ${ }^{72}$

This point was also emphasised in a recent paper by Benjamin and colleagues, who showed that ossification processes in the Achilles tendon of young rats are a physiological part of normal development. Bony spurs form without inflammatory reactions and they form by endochondral ossification of enthesis FC preceded by vascular invasion. ${ }^{73}$

\section{Treatment}

Successful treatment in an open study of 11 patients with AS with the anti-TNF $\alpha$ monoclonal antibody infliximab (Remicade) in a dose of $5 \mathrm{mg} / \mathrm{kg}$ body weight intravenously infused on three occasions (weeks 0,2 , and 6) was reported by Braun, Berlin. ${ }^{74}$ The patients with AS had severe disease that had not responded to conventional treatment, including sulfasalazine. The response was monitored over 12 weeks by visual analogue scale for pain, BASDAI - a disease activity index, BASFI- a functional index, BASMI-a metrology index, serum $C$ reactive protein and IL1. Dramatic 
improvement, starting on the day after the first infusion, was noted in all 10 patients who completed the study; one patient was withdrawn from the study because of rash. Improvement was still present at week 12 in nine of the patients. Pain and swelling due to enthesitis clearly improved in two patients. Similar results have been reported from Belgium. ${ }^{75}$ Thus anti$\mathrm{TNF} \alpha$ treatment seems to be effective in active AS, and deserves to be studied further in a controlled study, and also in other forms of SpA. ${ }^{76}$ As discussed by Khan, this is potentially the biggest breakthrough in the treatment of severe AS since the introduction of phenylbutazone more than 40 years ago.

We thank Dr M Benjamin and Dr R Francois for reading the manuscript and much helpful advice and discussion.

Professors Braun and Sieper are supported by grants from the Bundesministerium für Forschung und Technologie.

1 Braun J, Bollow M, Remlinger G, Eggens U, Rudwaleit M, Distler A, et al. Prevalence of spondylarthropathies in HLA B27-positive and -negative blood donors. Arthritis Rheum 1998;41:58-67.

2 Brown MA, Kennedy LG, MacGregor AJ, Darke C, Duncan E, Shatford JL, et al. Susceptibility to ankylosing spondylitis in twins: the role of genes, HLA, and the environment. Arthritis Rheum 1997;40:1823-8.

3 Dougados M, van der Linden S, Juhlin R, Huitfeldt B, Amor B, Calin A, et al. The European Spondylarthropathy Study Group preliminary criteria for the classification of spondylarthropathy. Arthritis Rheum 1991;34:1218-27.

4 Braun J, Sieper J. The sacroiliac joint in the spondylarBraun J, Sieper J. The sacroiliac joint in the spondy
thropathies. Curr Opin Rheumatol 1996;7:275-83.

5 McGonagle D, Khan MA, Marzo-Ortega H, O'Connor PO, Gibbon W, Emery P. Enthesitis in spondyloarthropathy. Curr Opin Rheumatol 1999;11:244-50.

6 Brandt J, Bollow M, Häberle HJ, Sieper J, Braun J. Not all patients with sacroiliitis have spondyloarthropathy - a clinical study of inflammatory back pain and arthritis of the lower limbs. Rheumatology (Oxford) 1999;38:831-6.

7 Benjamin M, Evans EJ, Copp L. The histology of tendon attachments in man. J Anat 1986;149:89-100

8 Rufai A, Ralphs JR, Benjamin M. Structure and histopathology of the insertional region of the human Achilles tendon. J Orthop Res 1995;13:585-93.

9 Benjamin M, Ralphs JR. Fibrocartilage in tendons and ligaments—an ad

10 Ralphs JR, Benjamin M. The joint capsule: structure, composition, ageing and disease. J Anat 1994;184:503-9.

11 Gao J, Messner K, Ralphs JR, Benjamin M. An immunohistochemical study of enthesis development in the medial collateral ligament of the rat knee joint. Anat Embryol collateral ligament of the
(Berl) 1996;194:399-406.

12 Gao J, Räsänen T, Persliden J, Messner K. The morphology of ligament insertions after failure at low strain velocity: an evaluation of ligament entheses in the rabbit knee. J Anat 1996;189:127-33.

13 Waggett AD, Ralphs JR, Kwan APL, Woodnutt D, Benjamin $M$. Characterization of collagens and proteoglycans at the insertion of the human achilles tendon. Matrix Biol 1998; 16:457-70.

14 Shichikawa K, Tsujimoto $M$, Nishioka J, Nishibayashi Y, Matsumoto K. Histopathology of early sacroiliitis and enthesitis in ankylosing spondylitis. In: Ziff $\mathrm{M}$, Cohen SB, eds. Advances in inflammation research. Vol 9. The spondyloarthropathies. New York: Raven Press, 1985.

15 McGonagle D, Gibbon W, O'Connor P, Green M, Pease C, Emery P. Characteristic MRI entheseal changes of knee synovitis in spondyloarthropathy. Arthritis Rheum 1998; 41:694-700.

16 Benjamin M, Rufai A, Ralphs JR. The mechanism of formation of bony spurs (enthesophytes) in the achilles tendon. tion of bony spurs (enthesophytes)
Arthritis Rheum 2000;43:576-83

17 Ball J. Enthesopathy of rheumatoid and ankylosing spondylitis. Ann Rheum Dis 1971;30:213-23.

18 Garcia-Ramirez M, Toran N, Andaluz P, Carrascosa A Audi L. Vascular endothelial growth factor is expressed in human fetal growth cartilage. J Bone Miner Res 2000;15: 534-40.

19 Francois RF, Gardner DL, Bywaters EGL. The sacroiliac joint in ankylosing spondylitis. Rheumatology in Europe 1995;24:87.

20 Francois R, Gardner D, Degrave E, Bywaters E. Sacroiliitis in ankylosing spondylitis is not merely enthesitis. Arthritis Rheum (in press).

21 Braun J, Bollow M, Eggens U, Koenig H, Distler A, Sieper $\mathrm{J}$, et al. Use of dynamic magnetic resonance imaging with fast imaging in the detection of early and advanced sacroiliitis in spondylarthropathy patients. Arthritis Rheum 1.itis in spondyla

22 de Vlam K, Mielants H, Veys EM. Involvement of the zygapophyseal joint in ankylosing spondylitis: relation to the
bridging syndesmophyte. J Rheumatol 1999;26:1738-45.
23 Laloux L, Voisin MC, Allain J, Martin N, Kerboull L, Chevalier X, et al. Comparative histological study of enthesitis in spondyloarthropathies [abstract]. Arthritis Rheum 1999;42:S402.

24 Braun J, Bollow M, Neure L, Seipelt E, Seyrekbasan F, Herbst $\mathrm{H}$, et al. Use of immunohistologic and in situ hybridization techniques in the examination of sacroiliac joint biopsy specimens from patients with ankylosing spondylitis. Arthritis Rheum 1995;38:499-505. 25 Costello P, Bresnihan B, O'Farrelly C, FitzGerald O. tis. J Rheumatol 1999;26:1117-24.

26 Fassbender HG, Fassbender R. Synovial characteristics of seron.

27 Ceponis A, Konttinen YT, Imai S, Tamulaitiene M, Li TF, $\mathrm{Xu} J \mathrm{JW}$, et al. Synovial lining, endothelial and inflammatory mononuclear cell proliferation in synovial membranes in psoriatic and reactive arthritis: a comparative quantitative morphometric study. Br J Rheumatol 1998;37:170-8.

28 Maerker-Hermann E, Fassbender HG, Kessler S, Thomssen H, Meyer-zum-Büschenfelde $\mathrm{KH}$, Blessing $\mathrm{M}$. Transgenic mice with an epidermal overexpression of bone morphogenic protein-6 present with psoriatic skin lesions and osteoarthropathy [abstract]. Arthritis Rheum 1997;40: S261.

29 Schilling F, Kessler S. Das SAPHO-Syndrom-Klinischrheumatologische und radiologische Differenzierung und Klassifizierung eines Krankengutes von 86 Fällen. Z Rheumatol 2000;59:1-28.

30 Rufai A, Ralphs JR, Benjamin M. Ultrastructure of fibrocartilages at the insertion of the rat Achilles tendon. J Anat 1996;189:185-91.

31 Ralphs JR, Benjamin M, Waggett AD, Russell DC, Messner $\mathrm{K}$, Gao J. Regional differences in cell shape and gap junction expression in rat Achilles tendon: relation to fibrocartion expression in rat Achilles tendon: relation

32 Rufai A, Benjamin M, Ralphs JR. The development of fibrocartilage in the rat intervertebral disc. Anat Embryol (Berl) 1995; 192:53-62.

33 Milz S, Putz R, Ralphs JR, Benjamin M. Fibrocartilage in the extensor tendons of the human metacarpophalangeal joints. Anat Rec 1999;256:139-45.

34 Benjamin M, Ralphs JR. The cell and developmental biology of tendons and ligaments. Int Rev Cytol 2000;196: $85-130$

35 Carlsen S, Hansson AS, Olsson H, Heinegard D, Holmdahl R. Cartilage oligomeric matrix protein (COMP)-induced arthritis in rats. Clin Exp Immunol 1998;114:477-84.

36 Smith RK, Heinegard D. Cartilage oligomeric matrix protein (COMP) levels in digital sheath synovial fluid and protein (COMP) levels in digital sheath synovial fluid

37 Leroux JY, Guerassimov A, Cartman A, Delaunay N, Webber C, Rosenberg LC, et al. Immunity to the G1 globular domain of the cartilage proteoglycan aggrecan can induce inflammatory erosive polyarthritis and spondylitis in $\mathrm{BALB} / \mathrm{c}$ mice but immunity to $\mathrm{G} 1$ is inhibited by covalently bound keratan sulfate in vitro and in vivo. J Clin Invest 1996;97:621-32.

38 Zhang Y, Guerassimov A, Leroux JY, Cartman A, Webber $\mathrm{C}$, Lalic $\mathrm{R}$, et al. Arthritis induced by proteoglycan aggrecan $\mathrm{G} 1$ domain in BALB/c mice. Evidence for $\mathrm{T}$ cell involvement and the immunosuppressive influence of keratan sulfate on recognition of $\mathrm{T}$ and $\mathrm{B}$ cell epitopes. J Clin Invest 1998;101:1678-86.

39 Li NL, Zhang DQ, Zhou KY, Cartman A, Leroux JY, Poole $\mathrm{AR}$, et al. Isolation and characteristics of autoreactive $\mathrm{T}$ cells specific to aggrecan G1 domain from rheumatoid cells specific to aggrecan G1 domain from rheu
arthritis patients. Cell Research 2000;10:39-49.

40 Jobanputra P, Choy EH, Kingsley GH, Sieper J, PalaciosBoix AA, Heinegard D, et al. Cellular immunity to cartilage proteoglycans: relevance to the pathogenesis of ankylosing spondylitis. Ann Rheum Dis 1992;51:959-62.

41 Poole AR. The histopathology of ankylosing spondylitis: are there unifying hypotheses? Am J Med Sci 1998;316:22833.

42 Guerassimov A, Zhang Y, Banerjee S, Cartman A, Webber C, Esdaile J, et al. Autoimmunity to cartilage link protein in patients with rheumatoid arthritis and ankylosing spondylitis. J Rheumatol 1998;25:1480-4

43 Kriegsmann J, Franklin BN, Gay RE, Taurog JD, Hammer RE, Brauer R, et al. Fusion of vertebrae and the sacroiliac joint by cartilaginous tissue in HLA-B27 transgenic rats. Verh Dtsch Ges Pathol 1996;80:334.

44 Weinreich S, Eulderink F, Capkova J, Pla M, Gaede K, Heesemann J, et al. HLA-B27 as a relative risk factor in
ankylosing enthesopathy in transgenic mice. Hum Immunol 1995;42:103-15.

45 Eulderink F. Pathology of ankylosing spondylitis. Spine 1990;4:507-28.

46 Eulderink F, Ivanyi P, Weinreich S. Histopathology of murine ankylosing enthesopathy. Pathol Res Pract 1998; 194:797-803.

47 Sieper J, Braun J. Pathogenesis of spondylarthropathies. Arthritis Rheum 1995;38:1547-54.

48 Bollow M, Fischer T, Reißhauer H, Backhaus M, Sieper J, Hamm B, et al. Quantitative analysis of sacroiliac biopsies in spondyloarthropathies: $\mathrm{T}$ cells and macrophages predominate in early and active sacroiliitis-cellularity correlates with the degree of enhancement detected by magnetic resonance imaging. Ann Rheum Dis 2000;59:135-40.

49 Braun J, Tuszewski M, Ehlers S, Haberle J, Bollow M, Eggens U, et al. Nested PCR strategy simultaneously targeting DNA sequences of multiple bacterial species in inflamma- 
tory joint diseases. II. Examination of sacroiliac and knee joint biopsies of patients with spondyloarthropathies and
other arthritides. J Rheumatol 1997;24:1101-5.

50 Wilkinson NZ, Kingsley GH, Sieper J, Braun J, Ward ME. Lack of correlation between the detection of Chlamydia trachomatis DNA in synovial fluid from patients with a range of rheumatic diseases and the presence of an antichlamydial immune response. Arthritis Rheum 1998;41: 845-54.

51 Wilkinson NZ, Kingsley GH, Jones HW, Sieper J, Braun J, Ward ME. The detection of DNA from a range of bacterial species in the joints of patients with a variety of arthritides using a nested, broad-range polymerase chain reaction. Rheumatology (Oxford) 1999;38:260-6.

52 Schumacher HR Jr, Arayssi T, Crane M, Lee J, Gerard H, Hudson AP, et al. Chlamydia trachomatis nucleic acids can be found in the synovium of some asymptomatic subjects. Arthritis Rheum 1999;42:1281-4.

53 Braun J, Yin Z, Spiller I, Siegert S, Rudwaleit M, Liu L, et al. Low secretion of tumor necrosis factor alpha, but no al. Low secretion of tumor necrosis factor alpha, but no other Th1 or Th2 cytokines, by peripheral blood mononuclear cells correlates with chronicity

54 Rudwaleit M, Siegert S, Yin Z, Eick J, Thiel A, Radbruch A, et al. TNF $\alpha$-production of patients with ankylosing spondylitis and HLA-B27 positives is lower compared with HLA-B27 negatives and correlates with a TNF promoter gene polymorphism. Ann Rheum Dis (in press)

55 Granfors K, Merilahti-Palo R, Luukkainen R, Mottonen T, Lahesmaa R, Probst $\mathrm{P}$, et al. Persistence of yersinia antigen in peripheral blood cells from patients with Yersinia enterocolitica O:3 infection with or without reactive arthritis. Arthritis Rheum 1998;41:855-62.

56 Schulz LC, Schaening U, Pena M, Hermanns W. Borderline-tissues as sites of antigen deposition and persistence - a unifying concept of rheumatoid inflammation? Rheumatol Int 1985;5:221-7.

57 Burgos-Vargas R, Vazquez-Mellado J. The early clinical recognition of juvenile-onset ankylosing spondylitis and its ognition of juvenile-onset ankylosing spondylitis and its
differentiation from juvenile rheumatoid arthritis. Arthritis Rheum 1995;38:835-44.

58 Leirisalo-Repo M, Helenius $\mathrm{P}$, Hannu $\mathrm{T}$, Lehtinen A, Kreula J, Taavitsainen $\mathrm{M}$, et al. Long-term prognosis of reactive salmonella arthritis. Ann Rheum Dis 1997;56: 516-20.

59 Lehtinen A, Taavitsainen M, Leirisalo Repo M. Sonographic analysis of enthesopathy in the lower extremities of patients with spondylarthropathy. Clin Exp Rheumato 1994;12:143-8.

60 Olivieri I, Barozzi L, Padula A. Enthesiopathy: clinical manifestations, imaging and treatment. Baillieres Clin Rheumatol 1998;12:665-81.

61 McGonagle D, Gibbon W, O'Connor P, Green M, Pease C, Emery P. Characteristic MRI entheseal changes of knee synovitis in spondyloarthropathy. Arthritis Rheum 1998; 41:694-700.

62 McGonagle D, Gibbon W, Emery P. Classification of inflammatory arthritis by enthesitis. Lancet 1998;352: $1137-40$.
63 Braun J, Bollow M, Seyrekbasan F, Häberle HJ, Eggens U, Mertz A, et al. Computed tomography guided corticosteroid injection of sacroiliac joint in patients with spondyloarthropathy with sacroiliitis: clinical outcome and followup by dynamic magnetic resonance imaging. J Rheumatol 1996;23:659-64.

64 Bollow M, Brandt J, Häberle HJ, Schmitz S, Sieper J, Hamm B, et al. Use of magnetic resonance imaging to detect spinal inflammation in spondyloarthropathy [abstract]. Arthritis Rheum 1998;41:S358.

65 Braun J, Bollow M, Sieper J. Radiology and pathology of the spondyloarthropathies. Rheum Dis Clin North Am 1998; 24:697-735.

66 Thomas JT, Lin K, Nandedkar M, Camargo M, Cervenka J, Luyten FP. A human chondrodysplasia due to a mutation in a TGF-beta superfamily member. Nat Genet 1996;12: 315-17

67 Erlacher L, McCartney J, Piek E, ten Dijke P, Yanagishita $\mathrm{M}$, Oppermann $\mathrm{H}$, et al. Cartilage-derived morphogenetic proteins and osteogenic protein-1 differentially regulate osteogenesis. J Bone Miner Res 1998;13:383-92.

68 Reddi AH. Initiation of fracture repair by bone morphogenetic proteins. Clin Orthop 1998;355(suppl):S66-72.

69 Wolfman NM, Hattersley G, Cox K, Celeste AJ, Nelson R, Yamaji $\mathrm{N}$, et al. Ectopic induction of tendon and ligament in rats by growth and differentiation factors 5,6 and 7 , members of the TGF-beta gene family. Clin Invest 1997; 100:321-30.

70 Hattersley G, Cox K, Soslowsky LJ, Thomopoulos S, Hewick R, Joyce ME, et al. Bone morphogenetic proteins 2 and 12 alter the attachment of tendon to bone in a rat model: a histological and biomechanical investigation. Transactions of the Orthopaedic Research Society 1998; 23:96.

71 Crew MD, Effros RB, Walford RL, Zeller E, Cheroutre H, Brahn E. Transgenic mice expressing a truncated Peromyscus leucopus TNF-alpha gene manifest an arthritis resembling ankylosing spondylitis. J Interferon Cytokine Res 1998;18:219-25.

72 Harper J, Klagsbrun M. Cartilage to bone-angiogenesis leads the way. Nat Med 1999;5:617-18.

73 Benjamin M, Rufai A, Ralphs JR. The mechanism of formation of bony spurs (enthesophytes) in the Achilles tendon. Arthritis Rheum 2000;43:576-83.

74 Brandt J, Haibel H, Cornely D, Golder W, Gonzalez J, Reddig J, et al. Successful treatment of active ankylosing spondylitis with the anti-tumor necrosis factor $\alpha$ monoclonal ylitis with the anti-tumor necrosis factor $\alpha$ m

75 Van den Bosch F, Kruithof E, Baeten D, De Keyser F, Mieants $\mathrm{H}$, Veys EM. Effects of a loading dose regimen of three infusions of chimeric monoclonal antibody to tumour necrosis factor $\alpha$ (infliximab) in spondyloarthropathy: an open pilot study. Ann Rheum Dis 2000;59:428-33.

76 Braun J, Sieper J. Anti-TNFa: a new dimension in the pharmacotherapy of the spondyloarthropathies!? Ann Rheum Dis 2000;59:404-6. 